\title{
Fear and Trembling
}

The Role of "Negative" Emotions in a Performative Pedagogy

\section{John Crutchfield}

If as educators we are serious about developing a performative pedagogy, then we must be prepared to embrace the full spectrum of emotions involved in aesthetic processes, including "negative" or unpleasant emotions such as anxiety, fear of failure and embarrassment, even sadness and anger. The following essay explores the role of such "negative" emotions in aesthetic processes, particularly where performance is concerned, and sketches out a conceptual framework based upon the anthropological notion of initiation, in which such emotions can be seen to have an important place in performative teaching and learning. The full and authentic embodiment of this understanding in the classroom, however, requires that teachers themselves be given practical, experiential training in aesthetic processes involving performance. Teaching itself, in other words, must first be seen in its correct light as a performing art. ${ }^{1}$

\section{Introduction: Darkness and Light}

As teachers, we have every reason to take seriously the findings of neuroscience. Learning is after all a brain activity, and those who teach would do well to consider how the brain actually learns. "Neuroscientific research," writes Michaela Sambanis, "offers powerful insights into the brain mechanisms that underly learning processes. These findings can give a better understanding of how learning happens, how the brain as organ of learning copes with stimuli, how it stores information, how it forms networks, and how competences are

\footnotetext{
${ }^{1}$ The text that follows is essentially the script for a talk the author intended to give at the academic conference "Drama and Theatre in Foreign and Second Language Teaching," held July $10^{\text {th }}-11^{\text {th, }} 2015$, at the Technical University in Reutlingen, Germany. What occurred instead was an impromptu discourse that dealt with similar themes but in a much less systematic way. Although the text retains certain verbal features that mark it as intended for oral delivery rather than print, a limited number of footnotes and textual references have been added for purposes of the present publication. The author wishes to thank Stefanie Giebert and the two anonymous reviewers for their helpful suggestions for improvements in this regard, and Micha Fleiner and Jonathan Sharp for the conversations that helped spark some of the central ideas of the essay.
} 
developed. In a nutshell, neuroscience can make substantial contributions when it comes to answering the multifaceted question of what helps and what hinders learning" (Sambanis 2016).

One of the more powerful neuroscientific findings, though at the same time perhaps one of the least surprising, has to do with the role of emotions in learning: the brain learns more efficiently when cognitive activity is accompanied by "positive" or pleasant emotions (Spitzer 2003). In fact, there is reason to suppose that this is the natural state of affairs, i.e. that learning is in itself pleasurable, and that Nature arranged things for us this way because, with neither sharp teeth and claws nor very much in the way of fur, our survival as a species has always depended on our ability to learn, and to learn all the time. (Or, conversely: because we could learn so well and so continuously, we required neither sharp teeth and claws, nor thick fur, etc. in order to survive.) As Aristotle observed long ago in the Poetics, pleasure is an important aspect of mimesis, and hence of learning; and even Immanuel Kant, that colossus of Rationalism, knew that every Bestimmung has its underlying Stimmung, and that one has to be, so to speak, "in the mood" for thinking.

The task of the teacher, then, is partly one of staging the learning process: of creating for learners an environment in which the natural pleasure of learning is supported and encouraged rather than hindered and undermined. For hindered and undermined it can certainly be if, instead of pleasant emotions, unpleasant or "negative" emotions, such as for example a fear of failure, are allowed to attach themselves to the material to be learned or to the learning process itself. Such emotions have long been seen to impede learning in all of its classic phases: input, processing and output (Tobias 1986).

I say that none of this is surprising because I assume most people have had personal experience, at some point and in some area of their lives, with both pleasant and unpleasant learning, and hence can attest to the qualitative difference. When learning is pleasurable, it feels easy.

When it is painful, it feels like a chore, and in the end we learn less and forget even that little we've learned more quickly. At first blush, then, the pedagogical answer seems obvious enough: we just have to make school fun.

Well, it doesn't take a Socrates to perform a reductio ad absurdum here. If positive emotions really were all that mattered in learning, we would be handing out oxycodone in the school cafeteria. That would infuse the learning process with positive emotions in no time flat, and yet it would probably be a bad idea. As a "thought experiment," however, it should make one thing clear: we don't actually believe that pleasure is the only, or even the most important aspect of learning. Or at least, not pleasure plain and simple. And why should we? Pain and pleasure co-exist in life in a sometimes inextricable knot. Not always, but often enough the greatest and most "sustainable" pleasures come through the dire straits of effort, pain and suffering. This is also true of aesthetic pleasure: it is the pathway of art as well as of life. Seeing the two as interconnected is both good dramatic structure and a healthy way to live. When they become polarized in our minds - when we pursue pleasure at face value and banish pain 
to the outer dark (or rather, to Other People), then the pleasures we experience remain superficial, easily taken for granted and soon forgotten, while bad and painful things that happen to us, the failures and betrayals, are experienced as a pure subtraction from life, an irreparable loss, an un-dialectical negation.

Do we really believe that we can banish all pain from the classroom and still persuade our students that what we're doing has any relation to their actual lives? How can we claim to address our students "holistically" if we refuse to acknowledge or are unprepared to deal with the dark side of their humanity-not to mention our own? Fear, grief, anger, desire: these things are disruptively real in life and they are the irreducible themes of art. Shouldn't they have a place in education, above all in an aesthetic education?

In other words, the desire to "instrumentalize" aesthetic processes for purposes of education is constantly in danger of throwing the baby out with the bathwater. We want the pleasure without the pain, forgetting that the pleasure without the pain is a different pleasure, a lesser pleasure, because part of the soul is being left out. And once that omission has been made, we're no longer in the realm of art, but of mere entertainment.

What I'd like to suggest is that an authentic teaching practice, a practice that embraces the full humanity of both teacher and student, leaves room for darkness as well as light. The question is not how to banish unpleasant emotions from the classroom so that learning can occur more efficiently, but how best to address unpleasant emotions when they do arise, how best to integrate them into the learning process in a way that serves the overarching goal of "transform[ing] brains into minds" (Eisner 2003: 341). This is no mean task; nor is it finally avoidable, especially for a pedagogy that seeks to make use of aesthetic experiences in an authentic way. But this is precisely where a performative pedagogy can be of greatest value. Performative approaches not only make room for negative as well as positive emotions, they are also ideally suited for integrating these emotions into a full experiential dramaturgy, a structure that supports learning in its most transformative aspect.

\section{The Art of Teaching}

The argument might go something like this: Any artistic process will, if fully embraced and by virtue of its holistic nature, produce both "negative" (or unpleasant) and "positive" (or pleasant) emotions. This is especially true of artistic processes involving performance, where the "work" is the body itself, or rather, embodied action before witnesses, and the performer is exposed in a profound, frightening and unpredictable way (in fact, this is what it means to perform.) Thus the attempt to repress or avoid unpleasant emotions is not only misguided, but may actually result in short-circuiting the very experience that artistic processes make uniquely available. The challenge for teachers who wish to use an aesthetic approach in their pedagogy is to manage these "negative" emotions in a constructive way, which first and foremost means acknowledging and integrating them consciously, through structured reflection, into the artistic 
process of which they are necessarily a part. But this in turn means that teachers themselves must be deeply familiar with, and fully competent in, the artistic processes in which they wish to engage their students. They must be fully cognizant of the artistry involved in their own praxis.

That, in a nutshell, is my claim. But before any of this can be made persuasive, I have to make a detour through the zone of some rather philosophical, but not entirely speculative, assertions about the nature of teaching. I would like to begin with the proposition that teaching is not just tangentially or metaphorically but fundamentally an art. Hopefully this idea strikes you as neither new nor absurd. If we accept this as our premise, then certain questions immediately arise. What kind of art is teaching? And if we know what kind of art it is, then: What sort of artistic training is required for its successful practice?

That teaching is first and foremost a performing art should be obvious to anyone who has ever had occasion to see it done. Though their styles of performance may vary to the point of utter idiosyncrasy, the best teachers are all, in their different ways, consummate performers. Like performers in other arts, one of the most important things they know is how to be present.

I say this is obvious; but for some reason the history of the idea, dating back at least to the Sophists of the $5^{\text {th }}$ century B.C.E., is marked by vast swathes of forgetfulness, when we have convinced ourselves that teaching is not an art at all but rather a science, modelled after horticulture or experimental physics or one of the other natural sciences. During these periods (which include most of the $18^{\text {th }}$ and $19^{\text {th }}$ Centuries in Europe and North America, for instance), "little or no attention was devoted towards exploration of the artistic or aesthetic features of teaching," for "[t]the model of human rationality ... was the scientist, not the artist" (Eisner 2002: 379). Although there have always been voices crying out in the wilderness (Goethe and Schiller in Germany, Rousseau in France, Coleridge et. al. in England) the last major swing back toward an emphasis on aesthetic education and an artistic concept of teaching occurred at the beginning of the $20^{\text {th }}$ Century with figures like Rudolf Steiner, John Dewey and William James. It seemed as though the fine arts would finally take their place not merely among the subjects regularly taught in school, but as a fundamental principle and method of education. Since then, however, the oscillation of reform and retrenchment has been dizzying: the immediate post-war period saw a significant swing back toward scientific rationalization, the 60's out again toward "affective learning" and open classrooms, the 70's back once again to more traditional methods, etc. - as Harry A. Dawe observed in 1984, before pushing the pendulum back the other way again in an article entitled, "Teaching: A Performing Art."

More recently, and particularly since the turn of the millennium, the push toward rationalization of education has once again asserted itself, albeit now under an explicitly corporate model with its characteristic rhetoric of "assessment," "outcomes," and "achievement." This model is now so pervasive and so deeply embedded in both public and private institutions, that Manfred Schewe's (2011) plea for a "performative teaching and learning culture" 
amounts to a political act of defiance. As libraries morph into "media centers," as chalkboards are replaced by smartboards and pen and paper by ipads, as classrooms turn virtual and learning goes online - with huge corporate interests at stake, mind you - what could be more absurd than to suggest that the best learning takes place in the flesh, with "head, heart, hand and foot," and that the performing arts - the arts of embodied presence par excellence - ought to be the soil in which good teaching and learning are grown?

But let's accept this quixotic idea anyway, if only for the sake of argument. If it is indeed a performing art, then teaching requires performance-oriented training. Certainly the training of theatre actors offers a plausible analogy, though the theatre is different from the classroom in decisive ways, and actor training is in itself extremely diverse. Both Dawe (1984) and Eisner (2002), for instance, propose the idea of the "teaching studio," based on the model of the acting studio, i.e. an actual facility and organization whose purpose is to train teachers experientially in their craft, and to provide a framework for professional feedback, critique and reflection. Such facilities should be an integral part not only of teacher education but also of in-service training. The aim, for Eisner, is to help teachers "learn to think like artists" (Eisner 2002: 384). Virtually identical language is to be found in the press material for most reputable North American actor training programs, as for example the BFA Acting Program at the Juilliard School of Drama, Dance and Music, each of whose graduates will "stand ready to embrace a life of continued learning as a generous, skilled, and deeply committed artist" (http://www. juilliard.edu/degreesprograms/drama/acting-programs, accessed 27.12.15). Moreover, the basic goal of all actor training, which I take to be the ability to move, speak, think, feel, sense, intuit, imagine, and react authentically in the present moment and with clarity of intention - this I take also to be the hallmark of good teaching.

There is, however, one fundamental difference between teaching and acting: the teacher must care about the people who constitute his or her "audience." Which means the teacher has to see these people not as an anonymous mass from whom something must be wrested (approval, recognition, money, prizes, adulation, "love," erotic desire, good teaching evaluations, etc.), much less as an enemy to be overcome (I think here of the theatre director Robert Wilson's legendary and oft-repeated advice to actors: "Hate the audience!"), but as individual instances of Human Being, each with a complex personal history and inner life whose depths can never be completely fathomed or understood. In a word, a mystery.

Thus care is rooted in a fundamental respect. It entails a "way of seeing" other people, a non-totalizing way, one that does not presume to know fully or to encompass, or better: whose encompassing is dialectical, leaving room for the mystery of each person, for (in the words of Shakespeare's Prospero) the "dark backward and abysm of time" no less than for the potential that may be realized in the future.

Moreover, when it comes to teaching, the concepts of care and respect (to which one must immediately add empathy and fairness) are not merely abstract 
ethical values, but personal moral qualities in the teacher him-or-herself. They have to do with who the teacher is. The teacher does not perform a fictional role in a fictional world the way an actor typically does. Even when the teacher chooses to "role-play" for pedagogical purposes (as "devil's advocate," for example, or "teacher-in-role"), the stakes are real and they are high, because the context of such "play" is ineluctably serious. Unlike the traditional theatre, in which actions and words function primarily as representation (mimesis), the classroom is a place in which these things are real and have real consequences. Real feelings get hurt. I might cry at a play in which a schoolboy is humiliated by his teacher, but in the back of my mind I never forget that these are actors playing characters, not a real teacher and a real schoolboy. And thus the suffering I seem to witness is merely symbolic. Even if, as sometimes happens in avant-garde theatre, the actor willingly submits himself to actual physical or emotional abuse on stage, it is finally in the service of an aesthetic experience for the audience (although, admittedly, for the actor himself such willing submission to abuse may also serve other, less innocent, perhaps even narcissistic, masochistic or otherwise psychopathological functions).

In other words, the characters in a play exist only in my mind as an audience member, by virtue of the actors' skill (and to be sure, the skills of the playwright, director, and designers as well) at activating my imagination and of my willingness to be thus activated. My tears themselves are real tears, but the occasion for them is imaginary. They are qualitatively - one might even say ontologically - different from the tears I might cry if I witnessed an actual schoolboy being humiliated by an actual teacher. In fact, I might not cry at all in this case, unless I happen to be "hardwired" in such a way that anger makes me cry. For then, far more important things are going on than my personal emotions: an act of cruelty to which I must, if as an adult I have any integrity at all, put a stop. To the degree that I am willing and able to witness this actual cruelty as merely aesthetic, and to enjoy aesthetically the feeling of being "moved to tears," I have essentially surrendered my moral agency. I might as well end by saying: Wow, that was intense. Shall we call a cab?

But cruelty, whether emotional or physical, is only an extreme form of the lack of care and respect. Let us hope it is also rare among teachers nowadays. In any event, it suffices that the teacher be merely unfair, disingenuous, manipulative, lacking in empathy, or simply unhappy in his or her profession: this will have a profoundly detrimental effect on the whole business of teaching and learning. I believe our friend John Hattie (2009) has proven this, at least indirectly. Who the teacher is actually matters - to an extent that can even be measured, if measurement is what you're into.

Hence a teacher does actually have to try to be a good person. What sort of person an actor is, by contrast, whether morally good or bad, makes no difference at all to the audience in a theatre. In fact, anecdotal evidence would suggest that actors, like professionals in many other highly competitive and uncertain fields, actually benefit from being relatively unencumbered by scruple. Not so in education. Granted, few of us can claim to be truly good, or 
even mostly good, no matter how hard we try to be it. Part of this is because being good (or mostly good) means acknowledging one's own fallibility and potential for evil. And yet, to recognize the fact that what sort of person you are actually matters in the classroom, and profoundly so, is at least to raise your eyes to a certain ethical standard. It may be unattainable, but that doesn't mean you shouldn't try to attain it.

Be that as it may, moral goodness - let's tone it down a bit now and speak of integrity instead -integrity is notoriously difficult to teach. Like creativity, some would say, it can be learned (or re-learned), but it cannot be taught. So for the question of teacher training, when we talk about a "performative" approach, we are generally left with things that we know can be taught, things like voice and diction, gesture and facial expression, posture, movement, breathing, listening, spacial awareness, improvisation, the use of silence, the dramaturgy of conflict, etc. In short: skills. If we cannot teach integrity, at least we can teach skills. Or if the word "skills" strikes us as too craftsman-like and instrumental, we can call them "competences." And alongside a deep knowledge of the subject and a solid familiarity with various pedagogical methods and techniques, perhaps this is enough. We know our material and we know how to stand up in front of an audience of students and perform.

But while absolutely necessary, these actorly skills in fact turn out to be far from sufficient causes of good teaching. In education, again as opposed to theatre, such skills only become meaningful-and effective-in the service of authentic performance, or rather, of the performance of authenticity. And by "performance" here I mean a public manifestation in word and deed. What is manifested? My actual character: my authenticity: who I am as a person. And thus the question of integrity confronts us once again.

In fact, we can't escape it. And this is as it should be. For if I do not actually care about my students as human beings, then none of my actorly skills, nor for that matter, my subject knowledge, my facility with pedagogical methods and techniques, my carefully planned lessons, etc. - none of it will make much difference. My students will feel, instantly, intuitively, that I am only pretending, that I am inauthentic, that I am, as one Holden Caulfield would say, a phony. And I will have lost their respect and with it my authority. At best, I may succeed in entertaining them every now and then. A few may learn something along the way. At worst I may destroy their faith in the whole enterprise of formal education. It may come to seem to them like just another game. Some of them may choose not to play; and that choice would probably be to their credit as human beings.

That's a worst-case scenario, of course. What usually happens in a classroom where the teacher is unable fully to perform his or her authenticity, is that everyone tacitly agrees to follow the path of least resistance, to play along just enough to get by, to make the best of the situation. There may not be much pleasure, but at least there won't be much pain either. 


\section{Liminality and Transformation}

Let me now propose several things, which I will at present make no attempt to defend.

- Integrity is not given but made.

- Integrity is apperceptive: it depends upon self-knowledge.

- Self-knowledge is gained primarily through liminal experience.

- Liminal experiences involve pain (psychic, emotional, physical).

In the anthropological understanding, which is also to a large degree the understanding current in the field of Performance Studies, liminal experiences are liminal in two ways: internal and external. The external threshold tends to be societal or even spacial: the experience occurs at the fringes or in the border-zones between socially coded spaces. Tribal cultures mark such spaces as sacred, i.e. as fundamentally different from the profane spaces of normal everyday life, either by placing them at an actual physical remove from the village, or by "retro-fitting" conventional spaces in ways that remove them from their utilitarian function (Eliade 1958). The internal threshold is the one between men and gods, or if you prefer, between conscious and unconscious. Liminal experiences bring us into these intermediate zones, which are of course porous, permeable, volatile, transgressive, and finally, transformative (Turner 1964). As with geography, so with society and the individual soul: maximum change occurs at the edges.

Again in tribal cultures, these liminal experiences are typically cultivated and controlled through religious rituals, most notably, initiation rites or rites of passage (van Gennep 1909). For better or worse, however, most of us in the post-industrial West now live in cultures without formal rites of passage, at least not in the religious sense, and hence we have to look elsewhere for the liminal experiences that lead to self-knowledge and, when all goes well, to integrity.

Perhaps you can already guess where I'm going with this. Artistic processes present just such experiences of liminality, and few artistic processes are as thoroughly liminal as those that lead to theatrical performance: performance before a live audience of witnesses. Here indeed we might speak of a complete initiation in all three of its classic phases: rites of separation, rites of transformation and rites of (re-)integration. The only thing missing, but it is crucial in an educational context, would be to see the experience this way. That is to say: we have to know, and we have to help our students to know, that this is what is happening, this is the ultimate meaning of what we're doing. Through artistic processes we are not only learning the material and gaining competences (social, communicative, intercultural, etc.), we are also forging our own integrity as human beings from the disparate elements within us.

I've been speaking here primarily of the experience of students i.e. schoolchildren, but the same applies of course to teachers-in-training. If 
we really want to help future teachers gain the self-knowledge that leads to integrity, one way to do that would be to offer them the aesthetic experience of theatrical performance, to make it, in fact, a fundamental part of their training.

Note that I'm not talking about merely "practicing." Obviously, if performance is the essence of what future teachers will be called upon to do every day of their careers, then the more practice they get at it the better, particularly in a context where they are given useful, detailed feedback and encouraged to reflect and experiment. The voice, the body, the courage to improvise, the capacity to listen and respond "in the moment"-all of this has to be trained and strengthened through coaching and practice. But as I have been suggesting, this strength becomes mere muscle-bulk without the integrity to guide it.

I mentioned pain earlier. If embraced on their own terms - which is necessary if they are to provide a truly liminal experience - artistic processes are not all fun and games. Yes, there is the zen-like bliss of the "flow experience"; yes, there is the ecstasy of discovery; yes, there is the sheer fun of making a creative mess alone or with other people. But this is only part of it, as any practicing artist can tell you. It can actually hurt to write a poem. And maybe it should, at least a little. As the American writer Jonathan Franzen says, writing is "a vehicle of self-investigation... a method of engagement with the difficulties and paradoxes of [one's] own life"; hence "unless the writer is personally at risk - unless the book has been in some way, for the writer, an adventure into the unknown; unless the writer has set himself or herself a personal problem not easily solved; unless the finished book represents the surmounting of some great resistance - it's not worth reading. Or, for the writer, in my opinion, worth writing" (Franzen 2012: 122, 130).

What Franzen says of writing fiction holds for other art forms as well, but is particularly true where theatrical performance is involved. Every experienced theatre artist knows that the rehearsal process is fraught with difficulties: violent emotions, radical uncertainty and self-doubt, terrifying vulnerability, erotic volatility, sometimes even physical danger. "Stage fright," which most of us have been taught to see as a weakness or failure, is in truth a quite natural response to the reality of the situation: in both rehearsal and performance, one is utterly ex-posed, "placed out there" in the fire of the live moment, in which something real and unpredictable is going to happen, something that one both desires and fears, something potentially transformative.

And transformation means á là Nietzsche that something will be created and something will be destroyed. This is, after all, the essence of initiation. For something to be reborn, it first has to die, and for the personal ego, that process of dying can be painful and sometimes even terrifying. Traditional rites of passage often symbolize this quite explicitly in images of death (Eliade 1958). And yet, if we're serious about the transformative power of artistic processes, we must be prepared to embrace these "negative" experiences as well. Artistic processes are holistic. You can't have the ecstasy without the agony. To skip straight to the fun is not only to cheapen and superficialize the whole process, and hence to render it essentially null and void qua liminal experience, but to 
treat students as if fun were all they cared about. They already get this insulting message every hour of every day and from every minutest contact with mass society and consumer culture; shouldn't their teachers treat them with more respect? Shouldn't their teachers be able to say: You are more than that. You are stronger and smarter than that. You deserve better. Let's make something real happen, here, now, together.

It's worth mentioning that the foreign language classroom presents a particularly overdetermined instance of this. There, we really are dealing with an experience, for beginners, of utter helplessness, utter powerlessness and near-perfect incompetence. In short: a kind of death. None of my previous ego-strategies are of much use to me when learning a new language. I have to begin again from nothing. No wonder, then, that so many FL learners experience debilitating anxiety, and are reluctant to speak the target language at all, even in class (Süleymanova 2011). Who wouldn't be reluctant to expose himself to near-certain failure? But viewed within the framework of initiation, these emotions are not only perfectly normal, they are also deeply ambivalent. Like the Roman god Janus, they face both ways, toward death and toward rebirth. They mark, in fact the intiatory period of "ordeals" (van Gennep 1909), the liminal phase of "betwixt and between" (Turner 1964), the transition from one "mode of being" to another (Eliade 1958): from being a monolingual speaker to being a multilingual speaker. Nor is this merely playing with words. Knowledge of a foreign language is a special kind of knowledge. It changes the knower in profound ways - not just cognitively, but in the imaginative and emotional life as well as in the body itself: the ear, the lips and tongue, the musculature of the face, the expressiveness of the hands, the kinaesthetic sense of proximity and distance, of friendship and enmity. Learning a foreign language quite literally means becoming other. In a very real sense, once you've entered a foreign language, you can't go home again. Because the foreign language has entered you as well, and the "you" that goes home won't be the same "you" that left.

Woe betide the teacher who underestimates the seriousness of this process, or who tries to ignore, repress, or cover over with fun and games the natural anxiety many FL students feel. How much better it would be to have a framework, a method and a training that would enable one to maximize this volatility and direct it toward the transformative aims of education.

\section{An Experiment}

Finally, I want to tell you briefly about a pilot study conducted at the Freie Universität Berlin to investigate the possible value of the experience of performance for students in the Department of English Didactics. (For a fuller report on the study, see Crutchfield 2015).

In a semester-long workshop, eight students were given fairly rigorous artistic training in the fundamentals of Creative Writing. Part of their task was to produce a modest portfolio of original creative texts in the conventional literary genres: creative non-fiction, fiction, poetry, and drama. At the end of the 
term, the students put on a Public Reading of their work in front of a general audience. Throughout the term, they were also required to keep a Course Journal, in which they wrote reflections upon their experiences not only with the in-class creative writing prompts and exercises, but in particular with the Public Reading itself, both before and after. These Course Journals were the chief source of qualitative data for the study.

What an analysis of these data revealed was that the Public Reading, as theatrical performance, fundamentally determined the students' experiences over the course of the term, and it did so in three senses: as anticipated event, as experienced encounter, and as reflected and recollected ordeal. Moreover, the emotions associated with these three phases turned out to be similar for all students, such that one is able to map a basic trajectory of moments from doubt, to fear, to happiness.

In some cases, the amplitude of the emotional curve was rather muted, such that instead of doubt we had mere reluctance, instead of fear, nervousness, and instead of happiness, mild satisfaction or relief. In other cases, however, the trajectory was amplified into something approaching the existential: instead of doubt we had outright antipathy and resistance, instead of fear, terror, and instead of relief, an intense joy. I'd like now to share with you a few excerpts from the Course Journal of one student who exemplified this more amplified trajectory.

From the very first moment in which we were proposed to hold a public reading at the end of the seminar, I have never hidden my aversion. [...] I have never been fond of public performances. I'm strongly convinced that performing requires a high level of self-confidence I don't believe I possess when it comes to expressing my feeling to an unknown audience. Surely being bullied as a teenager in occasion of the only school recital I ever took part in did undermine my self-confidence [...] In addition, being the English language so intrinsically linked with my emotions, the idea of reading out my texts written in English simply terrified me.

When it was my turn, I could not move. My hands were sweating and I just could not move from the chair, which is why I was the only one who read his text from the sofa. It was as if I had become a part of it, as if it was the chair itself holding those sheets of paper. I envied my classmates' nonchalance: they could go on the stage and "perform" so freely, they even look happy when they are done, I thought.

For a moment, while reading [my story], I felt as if I were alone in the room: of course I could hear some noise in the background but it was like being alone in a room that had no walls, nor doors or windows. It was a room of my own where I could hear myself reading. It was only when people started applauding that I realized what had just happened, my eyes dampened and I felt a shiver run down my spine. After having read my text I felt exceptionally good. Not only had my anxiety disappeared, but it became clear to me that the knot made of fears, memories, expectations, panic and apprehension that had been tightening all these years had finally started to loosen up. 
Although I myself am still uncertain as to its significance, the fact is that this student was also one of the two who, in my judgment, were most committed to the artistic process of Creative Writing as I laid it out in the course, and who produced texts that most nearly approached literary quality.

One thing seems clear, however: the "negative" emotions that the student experienced before (and even during) the Public Reading were not a "subtraction" from his overall experience of the event. On the contrary: it would appear that the degree to which the event was transformative for him is directly related to the emotional stakes he had going into it. I would even venture to suggest that the intensity of the "negative" emotions stands in direct proportion to the "positive" effect the student experienced in the end; and hence, considered diachronically, that the "negative" emotions actually opened the way or expanded the capacity for the positive emotions on the other side of the performance. Thus the initial resistance and fear, etc., far from being "negative" in the sense of a negation, were actually a necessary and integral part of this student's overall experience of the course. And as he himself acknowledges in his self-reflection, they were clearly symptomatic of the fact that the personal stakes for him were quite high, and hence that something real, something truly transformative, might happen in performance.

To view these painful emotions - I think we can now dispense with the term "negative" - as unwanted, unnecessary, or irrelevant would be a mistake. Although their intensity and quality may differ from person to person, they are natural, perhaps even desirable, and in any case unavoidable where artistic processes are concerned - particularly where theatrical performance is a part of that process. The key to unlocking their transformative potential, however, has to do with their conscious acknowledgement, reflection and integration into what I earlier called the experiential dramaturgy of artistic process. Negative emotions must be seen as part of a dynamic whole: a coherent phenomenology or trajectory of experiential moments.

The student not only learned something about himself, but clearly underwent a profound personal transformation in and through the experience of performance. He has forged an integrity for himself, and this integrity, one imagines, will open for him the possibility, as a teacher, of being a real person for his students, of being authentic, compassionate, caring and curious-irrespective of whether he chooses to use Creative Writing or performance as explicit pedagogical tools or even as a general approach in his classroom. But I suspect that, having experienced it for himself, he will do this too. And if he does, he'll be prepared to respond on the strength of his own authentic experience, with both skill and empathy.

\section{Conclusion}

The upshot of all this, and to return now to our starting point, is that as educators we need a more nuanced, more dynamic and more dialectical concept of emotion than the one we've become familiar with from scientific discussions 
of affect and cognition. As Michaela Sambanis (2016) is quick to remind us, "Bridging the gap... between brain research and didactics, as well as between research and practice, is a delicate task, since brain researchers usually do not work directly in educational contexts and those involved in teaching usually only have an outsider's perspective on neuroscience. This heightens the risk of misinterpretation and misapplication." Hence the importance, she says, of "translational research," i.e. research that would test neuroscientific postulates in the highly complex and differentiated environment of the live classroom. Unlike the laboratory, the classroom is a place where there is "interference" from all sides and all at once, where there can be no pure observer but only participants with more or less awareness of the dynamics of the moment in which they're also caught up, and where nothing can be replicated. The point of a performative pedagogy would be to shape these moments artistically, to engage our students as whole people by guiding them into and through the full transformative experience of aesthetic process. But certainly it would be wrong to expect our students to undergo something that we have not undergone ourselves, to enter a territory we ourselves have never entered.

\section{Bibliography}

Crutchfield, John (2015): Creative writing and performance in EFL teacher training: a preliminary case study. In: Scenario 9/1, 3-34

Dawe, Harry (1984): Teaching: a performing art. In: The Phi Delta Kappan $65 / 8,548-552$

Eliade, Mircea (1958): Rites and Symbols of Initiation: The Mysteries of Birth and Rebirth (trans. Willard Trask). New York: Harper

Eisner, Elliot (2003): The arts and the creation of mind. In: Language Arts 80/5: Imagination and the Arts, 340-344

Eisner, Elliot (2002): From episteme to phronesis to artistry in the study and improvement of teaching. In: Teaching and Teacher Education 18, 375-385

Franzen, Jonathan (2012): Farther Away. London: Fourth Estate

Hattie, John (2009): Visible Learning: A Synthesis of 800+ Meta-Analyses on Achievement. London: Routledge

Sambanis, Michaela (2016): Drama activities in the foreign language classroom: considerations from a didactic-neuroscientific perspective. In: Schewe, Manfred \& Even, Susanne (eds.) (in preparation): Performative Teaching, Learning, Research / Performatives Lehren, Lernen, Forschen. Berlin: Schibri Verlag

Schewe, Manfred (2011): Die Welt auch im fremdsprachlichen Unterricht immer wieder neu verzaubern: Plädoyer für eine performative Lehr- und Lernkultur! In: Küppers, Almut; Schmidt, Torsten \& Walter, Maik (eds.): Inszenierungen im Fremdsprachenunterricht: Grundlagen, Formen, Perspektiven. Braunschweig: Diesterweg, 20-31 
Spitzer, Manfred (2003): Lernen, Gehirnforschung und die Schule des Lebens. Heidelberg, Berlin: Spektrum Akademischer Verlag

Süleymanova, Ruslana (2011): Abbau der Sprechangst im Unterricht Deutsch als Fremdsprache. Eine empirische Untersuchung im Beispiel der Integrationskurse. Berlin: Verlag Dr. Köster

Tobias, Sigmund (1986): Anxiety and cognitive processing of instruction. In: Schwarzer, Ralf (ed.): Self-Related Cognition in Anxiety and Motivation. New Jersey: Erlbaum

Turner, Victor (1964/1987): Betwixt and between: the liminal period in rites of passage. In: Mahdi, Louse Carus; Foster, Steven \& Little, Meredith (eds.): Betwixt and Between: Patterns of Masculine and Feminine Initiation. La Salle: Open Court

van Gennep, Arnold (1909/2004): The Rites of Passage (trans. Monika Vizedom and Gabrielle Caffee). London: Routledge 